\title{
THE MODERN IMPOSSIBILITY OF MAKING ART LIKE THAT OF THE PAST. INTERVENTION PROPOSAL FOR THE TEMPLE OF SAN JUAN BAUTISTA, TOCHIMILICO, PUEBLA, MEXICO.
}

\author{
M. ELISA VERA LUNA ${ }^{1}$ \\ ${ }^{1}$ Universidad Popular Autónoma del Estado de Puebla (UPAEP) \\ Facultad de Arquitectura \\ e-mail: marthaelisa.vera@upaep.mx,www.upaep.mx
}

Keywords: Historical Structure, restoration theories, earthquake.

\begin{abstract}
Restoration proposal for the Temple of Saint John the Baptist in Tochimilco, Puebla, México, damaged by the earthquake on September 19 ${ }^{\text {th }}, 2017$. This proposal is based on the restoration article by the Mexican architect José Villagrán García, his arguments are based on the modification of the architectural values after a restoration project. This must take into account the respect for the authenticity of the original element but must also seek to adapt to the time and requirements of its current environment. Taking these points, a recovery of the space is proposed, consolidating the ruin and using modern materials to fill the gaps left by the earthquake.

It is sought that this line of restoration be followed more and more in order to identify the historical stages in the life of the monuments.
\end{abstract}

\section{THE EARTHQUAKE}

On September 19th, 2017 a 7.1-magnitude earthquake hit central México. The epicenter was located $12 \mathrm{~km}$ southeast of the municipality of Axochiapan, close to the boundaries between the states of Morelos and Puebla, and $120 \mathrm{~km}$ south from Mexico City. The quake was caused by a rupture within the tectonic plate of Cocos, at a depth of $57 \mathrm{~km}$. Interplate earthquakes aren not common in the region but they are not unusual either.

According to the UNAM's network of seismographs and accelerometers, the quake's maximum acceleration reached $57 \mathrm{gal}^{1}$. Using the seismograms' data, the quake's spectral acceleration can be calculated.

This information provides insight into the behavior of buildings of various heights during the quake. Buildings having between 1 and 12 levels experienced an average acceleration of 119 gal; whilst those having between 12 and 24 levels experienced an acceleration of 60 gal. This data thus explains why the most damaged structures were the ones having between 4 and 7 levels.

The states with most recorded damage caused by this earthquake are Chiapas, Oaxaca, Morelos, Puebla and Mexico City. 


\section{TEMPLE OF SAINT JOHN THE BAPTIST, TOCHIMILCO}

The temple of Saint John the Baptist is located in the municipality of Tochimilco, in the western part of the state of Puebla, close to the state of Morelos, $14 \mathrm{~km}$ from the Popocatepetl volcano and $46 \mathrm{~km}$ of Axochiapan, Morelos, the epicenter of the earthquake. The temple dates from the end of the XVIII century, though there are maps from 1743 indicating an abandoned shrine in the same location. The shrine was dedicated to Saint John which may mean that some of the original structure was reused to build the existing temple.

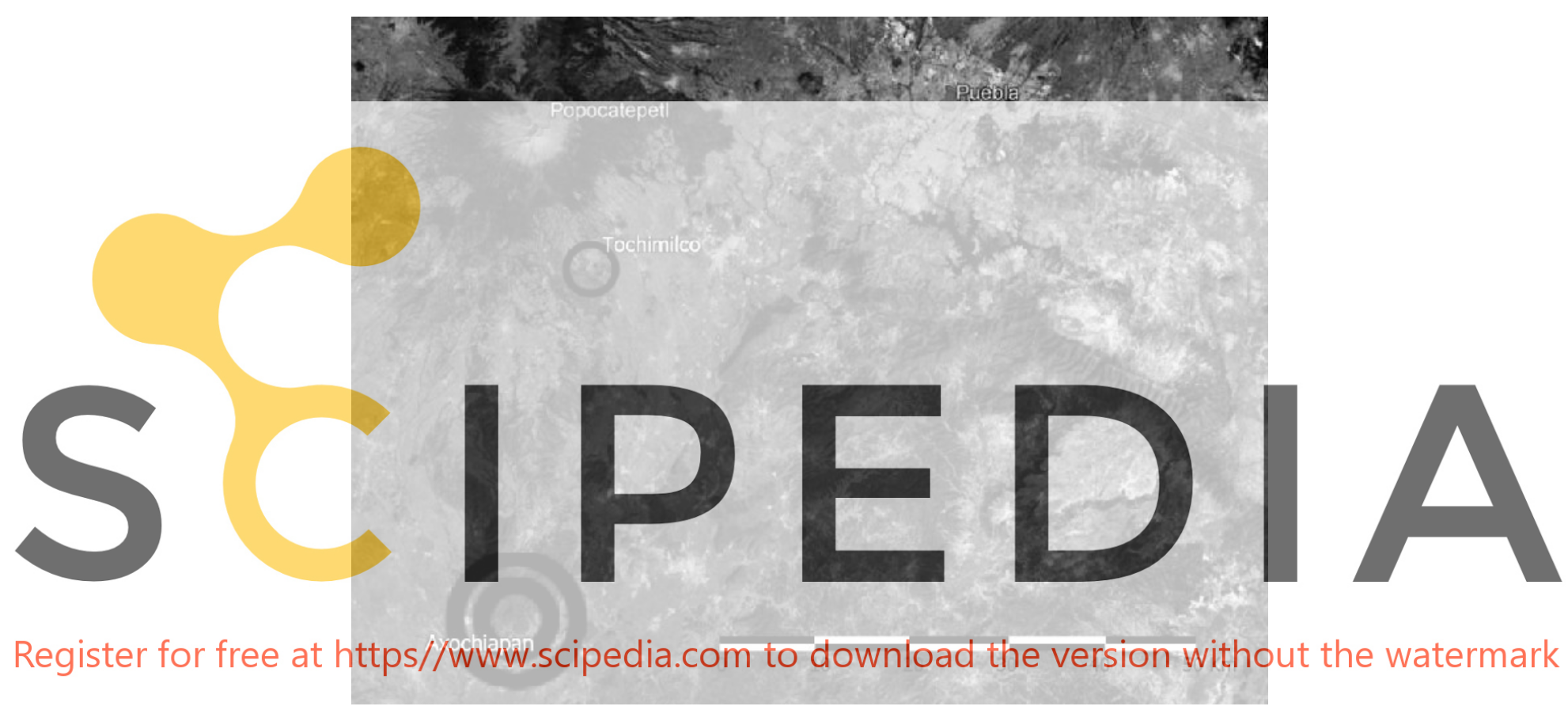

Figure 1. Localization of Tochimilco

The temple is a simple structure with a rectangular base of 7 by 14 meters and a height of approximately 6 meters. It was built over a promontory which is part of a structural block seemingly shaped by a geological fault line and covered with volcanic ashes. The nave is divided into two bodies covered by groin vaults. The north wall is made of irregular stone masonry, earth mortar joints, crowned by two rest arches with rock keystones and, between each keystone, 3 brick courses. The south wall and the façade have a base of approximately 2 meters. The base is of irregular stone masonry and earth joints and continues with a wall of mud bricks and earth mortar joints. The main wall and buttresses are made of irregular stone masonry. The groin vaults are made of stone cyclopean mixture and, unlike the rest of the building, their joints have lime mortar, evidence of them being built at a later date. Attached to the temple and on the north side, there are a sacristy and a warehouse, two rectangular spaces 
of 5 by 4 meters each. Their walls are made of irregular stone masonry and the roof cover of square clay and rooftop. A bell tower is also attached to the temple on the north side of its façade. The tower has a base of 3 by 3 meters and a circular core of 2 meters of diameter and 7 meters of height, covered with scrap stone masonry that gives it a rectangular shape. The tower is composed of two bodies crowned by a cupola.

Finally, in recent years a warehouse and a bathroom module were attached to the south façade. They were built with concrete bricks, rebar structures and solid slabs of steel and concrete. The frames were anchored to the temple walls.

\section{DAMAGES}

The temple of Saint John the Baptist was one of the most affected buildings by the earthquake of September $19^{\text {th }}, 2017$. Only $30 \%$ of the total structure stood after the quake. The amount of damage sparked controversy over the restoration procedures fit for this particular case.

During the quake and due to its slender shape, the bell tower suffered a displacement which led to its collapse. The tower collapse also collapsed the temple's façade. The addition of rooms to the sides of the temple, warehouses on the left and sacristy on the right, strengthened the bases of the walls around the altar. Hence, these walls moved at a different frequency than the

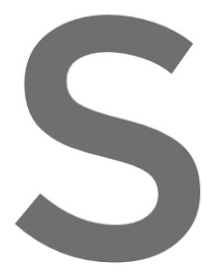
first body of the nare collapse of the vaults. area and loss of material. The binding with the main
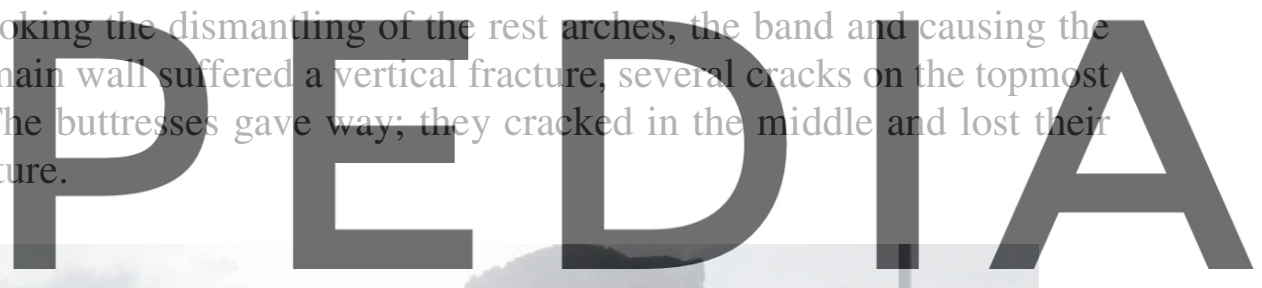

Register for free at https//www.scipedia.com to download the version without the watermark

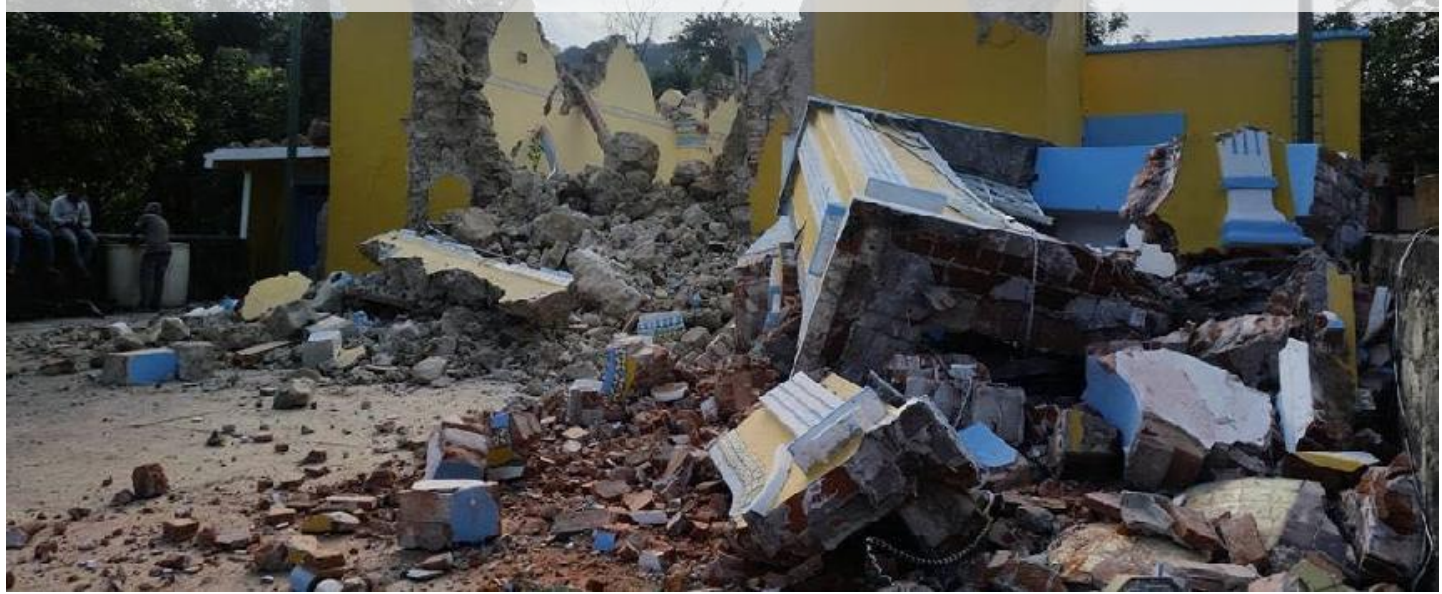

Figure2. San Juan Bautista after 19 September earthquake. 
The sacristy, recently intervened by replacing timber beams with concrete beams, presented minor fractures in its walls and floors. The concrete warehouses, built in recent years, were left under the side walls' debris.

The internal layers were bashed, allowing detailed observation of the construction system as well as the adjustments done to the temple, such as a decommissioned door from the nave to the sacristy and a mural painting on the altar wall. Some defects inside the walls were also revealed.

\section{RESTORATION PROJECT}

\subsection{Theoretical criteria followed by José Villagrán García}

The criteria used for this restoration proposal are based on the premises stated by the Mexican architect José Villagrán García. These premises are described in his article Arquitectura y Restauración de Monumentos (Architecture and Monument Restoration) ${ }^{2}$. In his text, Villagrán seeks to ignite a reflection on the role played by the architect faced with the restoration of a historic monument, rather than to line up an absolute working theory.

To guide up in that reflection he uses the, apparently contradictory, theories of Ruskin and Viollet-le-Duc. He also emphasizes the precepts set by the 1964 International Charter for the

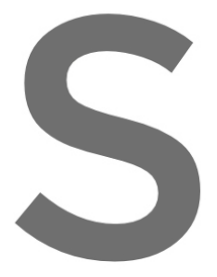

Conservation and Rest

He takes Ruskin natural state. He then state in which it could through interventions these two notions in mind,
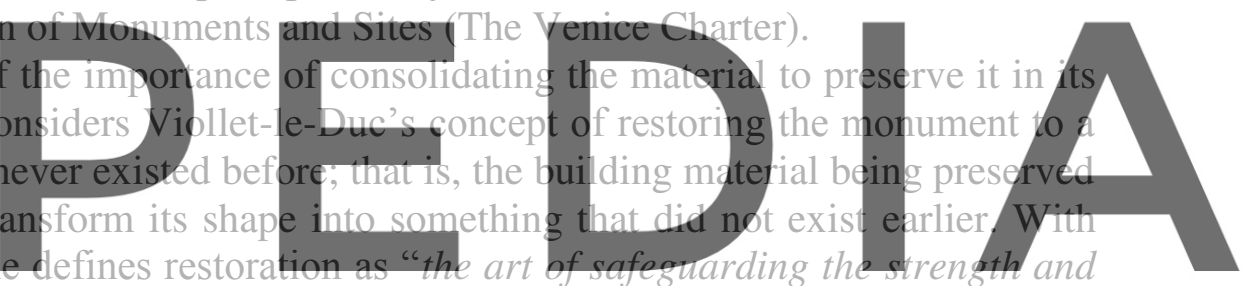

historic shape-material of the monument employing operations and additions that illustrate its

Register forcfneenatedattips aydwynwcsicipediancoim to download the version without the watermark

This definition is also underpinned by The Venice Charter's articles which state that in any procedure one must prioritize the respect to antique material, clearly marking the intervention in any supplemental work so that historical forgeries are avoided and future generations can easily read the different construction stages. To support that point, the Charter suggests researching exhaustively the building's background and its intervention records.

For Villagrán, the monument to be restored belongs to two architects, the one who initially builds it and the one who is in charge of restoring it, thus becoming the link joining the arts of building and restoring. To proceed with the restoration the architect should take into account four fundamental values of architecture: usefulness, the factological, esthetics, social. After a disaster and mainly after a restoration project those four values are modified. Usefulness, even if potentially maintained, is diminished in order to cover modern needs. As the factological relates to the consistency between the form and its function; it will be necessary to consolidate the building and, in some cases, to change the building materials in order to guarantee the function of the spaces. Esthetic value is most impacted since it is impossible to resurrect what fell apart. In time, it can be reproduced based on previous records, yet this new creation cannot 
acquire the value of authenticity from the original. Finally, regarding the social theme, since original parts subsist, the socio-historical value of the monument is evident for the community that envelops it.

The damaged monument becomes the mediator between the culture that sourced it and the current one welcoming it and adapting it to guarantee its continuity. This adaptation would always have to be performed by qualified architects, holding a good grasp of the building materials, the history and the culture that birthed the building and the current needs of the community using it.

\subsection{Proposal}

Considering the previous criteria and restoration as a multidisciplinary activity needing the expertise of engineers, architects, historians, geo-technicians, etc; studies on the walls' resistance were made for the proposal to respond to the current state of the structure.

The study corroborated that the walls are made of three layers, two external layers of stone secured with earth mortar and a core made of smaller stone mixed with earth and lime. The core has lost cohesion and has started to decouple the external layers causing the collapse in some areas. Furthermore, regions saturated with humidity and cavities were found. This means that the walls are working unevenly and cannot support the structural weight of reintegration with
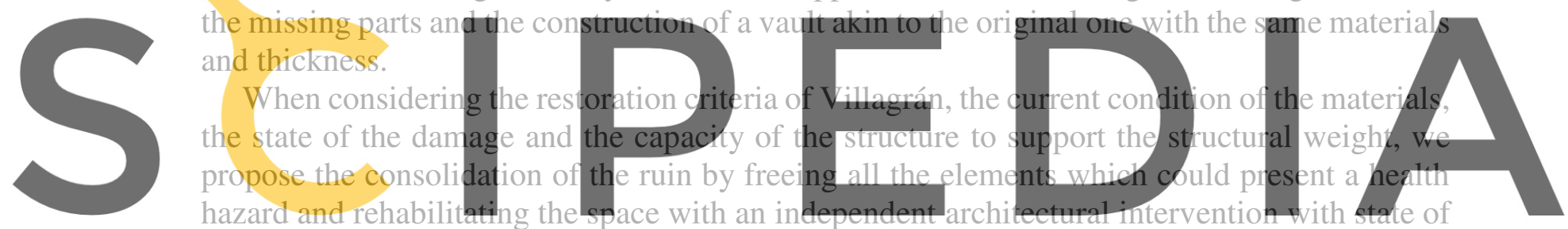

hazard and rehabilitating the space with an independent architect systems whilst keeping the proportions and original shapes.

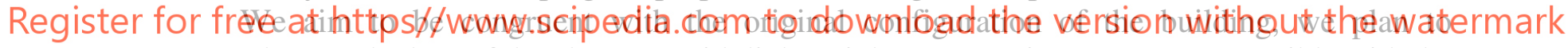
supplement the loss of the elements with lightweight construction systems compatible with the original systems that also harmonize with the entire set. In addition, we plan the removal of all the recent elements that do not provide aesthetical value and that concentrate rigidity in some areas of the building.

To consolidate the wall's stumps, we plan to inject slip, a fluid mixture of clay, in the joints, and patching up the cracks when needed. The crowning of the walls, up to the original heights, will be built with mud bricks and plastered with earth mortar. For the roof, we will craft a timber framework covered with clay roof tiles. Such framework will be composed of certified timber, kiln-dried, treated with sealers, flame-retardants, and anti-xylophages. The proposed system consists of a gabled roof with two side-skirts and ridge pitched between $30^{\circ}$ y $40^{\circ}$ and covered with flat clay roof tiles. To support the roof we propose an internal metallic structure detached from the temple walls so that it can also recreate the geometrical shapes of the arches and groin vaults to facilitate the reading of original elements that are still standing. We propose to build the façade according to the documentation to keep the identity of the temple and to rebuild the 
bell tower following the proportions of the original tower but with lesser height to reduce the oscillating motion in future quakes.

This type of intervention reignites the controversy over the usage of original techniques and modern materials. However, on some occasions, it is not possible to correct structural weakness with a traditional solution and lacking qualified labor. Thus we appeal for the usage of modern techniques so that the useful life of this building is prolonged. We reiterate that these actions must be performed by experts and be always bounded by the compatibility of modern and original materials, the durability of the intervention and the feasibility of the removal of additions in the future without affecting the original structure ${ }^{3}$.
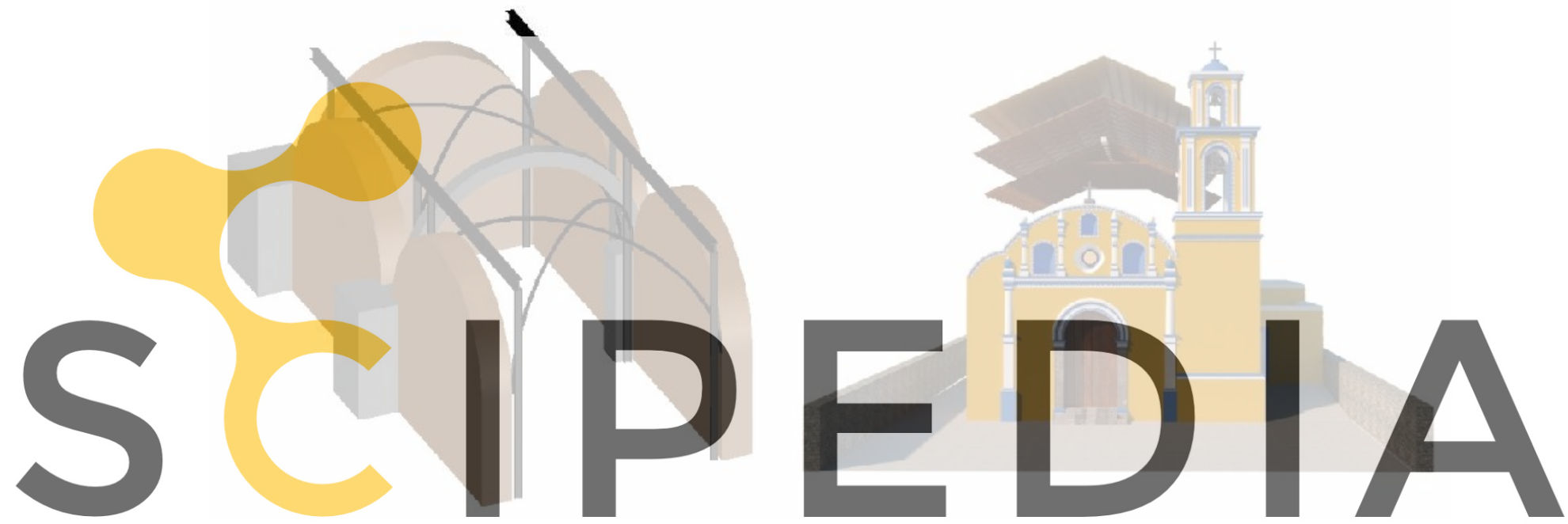

Figure3. Internal and external views of the proposal.

Figure3. Internal and external views of the proposal.
.scipedia.com to download the version without the watermark

\section{CONCLUSIONS}

We seek to discard imitations and historical forgeries lacking insight on the here and now from the original structure. Additionally, we hold a commitment with the future generations; we aim to leave a heritage site true to its story whilst preserving the temple ruins as a homage to the people who built it. We understand building intervention not as a hostile action against historical elements but as a dialogue with the past where we seek to respect its permanence in history whilst imprinting life purpose and constant transformation.

For this proposal, we hold the responsibility of laying it out such that the project becomes a strong link in the constructive historical chain of the community. We aim for this proposal to hold durability standards that can be equated to the one from the initial construction. With these elements in mind, we lay out a proposal only contingent upon the limitations of the original building. Far from silencing the architectural voices of the past, we want to let the original building speak. 
Acknowledgements. To the National Institute of Anthropology and History (INAH) and the Architect Teresita Miravete, for their support in the process of restoration of the building, Dr. José Ortega Ramírez and the work team of the Geophysics Laboratory of the National Institute of Anthropology and History to be carried out the study of resistivity, to the architect Antonio Zepeda and the company MIRC for facilitating the architectural surveys and three-dimensional models of the proposal, as well as the permanent access to the restoration

\section{REFERENCES}

[1] Cruz, V., Krishna, S., Ordáz, M., ¿Qué ocurrió el 19 de septiembre de 2017 en México? Ciencia UNAM, recuperado de http://ciencia.unam.mx/leer/652/-que-ocurrio-el-19-deseptiembre-de-2017-en-mexico-. (2017)

[2] Villagrán García, J. Doctrina de la arquitectura. El Colegio Nacional, (2007).

[3] Meli, R. Ingeniería Estructural de los Edificios Históricos. Fundación ICA, (1998)
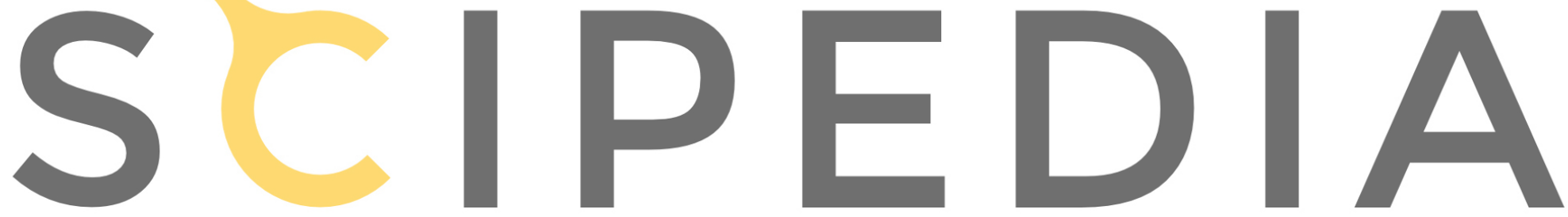

Register for free at https//www.scipedia.com to download the version without the watermark 